\title{
RESPON PARAMETER KARDIOVASKULAR (TEKANAN DARAH DAN NADI) TERHADAP PIJAT KAKI PADA KLIEN PREHIPERTENSI
}

\section{CARDIOVASCULAR PARAMETER (BLOOD PRESSURE AND PULSE) RESPONSE TO FOOT MASSAGE AMONG PREHIPERTENSION CLIENTS}

\author{
Evelin Malinti ${ }^{1}$, Mursito Hutagalung ${ }^{2}$ \\ Fakultas IImu Keperawatan, Universitas Advent Indonesia \\ Email: evelinmalinti@yahoo.com
}

\begin{abstract}
ABSTRAK
Pendahuluan: Hipertensi telah dikenal sebagai faktor resiko penyakit kardiovaskular dan menjadi penyebab kematian. Hipertensi memperberat kerja jantung dan dapat menimbulkan penyakit pembuluh darah. Pijat kaki memberi efek relaksasi dengan mempengaruhi sistem saraf otonom, mendilatasi pembuluh darah dan menurunkan tekanan darah. Tujuan: Penelitian ini dilakukan untuk mengetahui efektivitas pijat kaki pada tekanan darah dan nadi klien dengan pre-hypertensi. Metode: Penelititian ini menggunakan pra-eksperimental dengan design one group pre dan post test. Sebanyak 20 orang partisipan berusia 20-30 tahun menjadi sampel penelitian yang dipilih secara purposive sampling. Hasil: Rata-rata tekanan darah sistolik 131.60 $\mathrm{mmHg}$ sebelum pijat kaki menjadi $121.55 \mathrm{mmHg}$ setelah pijat kaki. Rata-rata tekanan darah diastolik $83.65 \mathrm{mmHg}$ sebelum pijat kaki menjadi $72.85 \mathrm{mmHg}$ setelah pijat kaki. Rata-rata nadi sebelum pijat kaki adalah $71.60 \mathrm{kali} /$ menit menjadi $64.80 \mathrm{kali} / \mathrm{menit}$ setelah pijat kaki. Uji statistik dengan paired $t$-test menunjukkan terjadi penurunan signifikan tekanan darah sistolik dan diastolik serta denyut nadi per menit setelah pijat kaki $(\alpha<.05)$. Diskusi: Penurunan tekanan darah baik sistol dan diastol serta nadi pada klien prehipertensi setelah pijat kaki merupakan respon fisiologis terhadap kondisi relaksasi yang merupakan efek dari pijat kaki.
\end{abstract}

Kata Kunci: Tekanan Darah, Nadi, Prehipertensi, Pijat kaki

\begin{abstract}
Introduction: Hypertension has been recognized as a risk factor for cardiovascular disease and causes of death. Hypertension adding workload to the heart and causing vascular disease. Foot massage give a relaxation effects by influencing the autonomic nervous sistem, dilated blood vessels, and reducing blood pressure. Purpose:This study was executed to know the effectivity of foot massage on blood pressure and pulse of clients with prehypertension. Method:This study utilized pre-experimental with one group pre and post-test design. A total of 20 participants with age 20-30 years old being sample of this study and was chosen by purposive sampling. Results: The mean of systolic blood pressure $131.60 \mathrm{mmHg}$ before foot massage became 121.55 $\mathrm{mmHg}$ after foot massage. The mean of dyastolic blood pressure $83.65 \mathrm{mmHg}$ before foot massage became $71.85 \mathrm{mmHg}$ after foot massage. The mean of pulse before foot massage is 71.60 beat/min became 64.80 beat/min after foot massage. Statistical test using Paired t-test shows significant reduction of systolic and dyastolic blood pressure, along with pulse rate per minute after foot masssage $(\alpha<.05)$. Discussion:The Reduction of systolic and dyastolic blood pressure, with pulse of prehypertension clients after foot massage was a physiologic response to realxation condition as an effect of foot massage.
\end{abstract}

Keywords: Blood Pressure, Pulse, Prehypertension, Foot Massage
JURNAL

SKOLASTIK

\section{KEPERAWATAN}

Vol, 4, No. 1

Januari - Juni 2018

ISSN: $2443-0935$

E-ISSN 2443 - 1699 


\section{PENDAHULUAN}

Tekanan darah tinggi atau yang dikenal dengan sebutan hipertensi dapat menambah beban jantung, menyebabkan kardiomegali, arteriosklerosis, kerusakan otak, ginjal dan mata (Daniel \& Nicoll, 2012). Peningkatan denyut jantung atau nadi dihubungkan dengan peningkatan tekanan darah; apabila dialami oleh penderita hipertensi hal ini meningkatkan resiko penyakit kardiovaskular (Reule \& Drawz, 2012).

Tekanan darah adalah kekuatan darah dalam menekan dinding pembuluh darah. Setiap kali berdetak jantung akan memompa darah melewati pembuluh darah. Tekanan terbesar terjadi ketika jantung memompa darah (dalam keadaan kontraksi), dan ini disebut dengan tekanan sistolik. Ketika jantung beristirahat (dalam keadaan mengembang), tekanan darah berkurang dan disebut tekanan diastolik (Puspitorini, 2008, hlm. 2).

Tekanan darah 120/80mmHg tidak lagi bisa disebut sebagai tekanan darah normal karena menurut JNC7 ini telah digolongkan sebagai prehipertensi. Tekanan darah meningkat sesuai dengan umur, tetapi usia muda tidak terlepas dari kemungkinan mengalami peningkatan tekanan darah. Tekanan darah sangat bervariasi tergantung pada keadaan. akan meningkat saat aktifitas fisik, emosi, dan stress (Wolfr, 2009, hlm. 5).

Menurut Berg (2017), semakin banyak orang dewasa muda yang mengalami tekanan darah diatas normal. Namun orang berusia dewasa muda sering mengabaikan kondisi ini. Kurang sadar akan kondisi dan tidak mendapatkan penanganan adalah alasan terjadi hipertensi diusia muda
(Yoon, Burt, Louis, \& Carroll, 2012). Padahal usia dewasa muda merupakan interval umur yang sangat penting untuk melakukan pencegahan dan penanganan hipertensi untuk mengurangi resiko penyakit kardiovaskular diusia yang lebih lanjut (Zhang \& Moran, 2017).

Peningkatan tekanan darah pada usia dewasa muda disebabkan oleh obesitas, gaya hidup sedentari, konsumsi makanan tinggi garam dan lemak (Kini, Kamath, Kulkarni, Kamath, \& Shivalli, 2016; Senthil \& Krisnadasa, 2016)). Mucci et al. (2016) mengatakan selain faktor-faktor diatas, kecemasan dan stess juga mempengaruhi tekanan darah pada mahasiswa. Beberapa penelitian sebelumnya (Biondi \& Picardi, 1999; Black \& Garbutt, 2002; \& Suter et al. 1997) dalam Moyle et al. (2014), menuliskan bahwa kecemasan dan stress dapat meningkatkan tekanan darah dan kecepatan nadi.

Teknik relaksasi dapat menghilangkan stress yang selanjutnya menurunkan tekanan darah dan kecepatan nadi. Pemijatan pada titik-titik tertentu ditelapak kaki dapat menimbulkan relaksasi tubuh secara umum, dengan demikian memberi hasil positif bagi tekanan darah dan nadi (Embong, Soh, Ming, \& Wong, 2015). Wahyuni (2014), menjelaskan bahwa pemijatan pada kaki dapat menurunkan hormon kortisol, merelaksasi tubuh dan menurunkan tekanan darah, dan mampu memberi rangsangan yang memperlancar aliran darah. Hal ini dibuktikan oleh penelitian yang dilakukan oleh Herliawati (2011), bahwa pemijatan pada kaki dengan minyak lavender, menurunkan tekanan 
darah sistolik maupun diastolik secara signifikan.

\section{BAHAN DAN METODE PENELITIAN}

Penelitian ini merupakan jenis praeksperimen dengan one group pre and post test design. Pemilihan sampel dilakukan dengan teknik purposive sampling untuk memperoleh partisipan sesuai kriteia inklusi. Data yang diperoleh di analisa dengan SPSS untuk mendapatkan deskriptif statistik untuk nilai rata-rata dan standard deviasi paired $t$-test, untuk melihat perbedaan parameter kardiovaskular sebelum dan sesudah pijat kaki.

Calon partisipan diukur tekanan darah sebanyak 3 kali dalam waktu 3 minggu. Calon partisipan yang memiliki tekanan darah yang termasuk kategori prehipertensi yang didapat selama 3 kali pengukuran diminta untuk berpartisipasi dalam terapi pijat kaki. Sebelum dan sesudah 30 menit pijat kaki, partisipan diukur tekanan darah dan pulse. Pengukuran tekanan darah dilakukan didaerah brachial lengan kiri partisipan menggunakan sphymomanometer digital. posisi berbaring terlentang menggunakan satu bantal.

Prosedur pijat kaki dilakukan selama 4 hari berturut-turut disore hari pada pukul 15.0018.00. Setiap partisipan menerima satu kali pemijatan kaki selama 30 menit, 5 partisipan sehari. Pijat kaki dilakukan pada partisipan dengan posisi terlentang diatas kasur, 15 menit untuk masing-masing kaki yang terlebih dahulu diolesi dengan baby oil. Secara berurutan teknik pemijatan dilakukan dengan teknik pembukaan, teknik inti dan teknik penutup.

\section{HASIL}

Sebanyak 20 partisipan yang memenuhi kriteria inklusi yaitu memiliki tekanan darah kategori prehipertensi dan menandatangani informed consent. Tekanan darah sistol dan diastol serta nadi partisipan sebelum pijat kaki ditunjukkan dalam tabel 1.

Tabel 1. Tekanan darah dan nadi sebelum pijat kaki

\begin{tabular}{llll}
\hline No & Sistol & Diastol & Nadi \\
\hline 1 & 136 & 83 & 71 \\
2 & 126 & 82 & 68 \\
3 & 127 & 84 & 63 \\
4 & 131 & 83 & 64 \\
5 & 126 & 84 & 69 \\
6 & 131 & 84 & 65 \\
7 & 129 & 84 & 76 \\
8 & 132 & 88 & 78 \\
9 & 129 & 84 & 80 \\
10 & 139 & 88 & 61 \\
11 & 132 & 89 & 78 \\
12 & 136 & 81 & 76 \\
13 & 120 & 82 & 71 \\
14 & 139 & 86 & 90 \\
15 & 131 & 80 & 68 \\
16 & 139 & 84 & 78 \\
17 & 126 & 80 & 68 \\
18 & 138 & 86 & 68 \\
19 & 130 & 80 & 69 \\
20 & 133 & 81 & 71 \\
\hline
\end{tabular}

Rata-rata tekanan darah sistolik, tekanan darah diastolik, dan nadi sebelum dilakukan pijat kaki ditunjukkan dalam tabel 2.

Tabel 2. Rata-rata tekanan darah dan nadi sebelum pijat kaki

\begin{tabular}{lll}
\hline Parameter & Mean & SD \\
\hline TD Sistolik & 131.50 & 5.196 \\
TD Diastalik & 83.55 & 2.700 \\
Nadi & 71.60 & 6976 \\
\hline
\end{tabular}


Hasil pengukuran parameter: tekanan darah sistolik, diastolik, dan nadi setelah dilakukan pijat kaki selama 30 menit dapat dilihat pada tabel 3 .

Tabel 3. Tekanan darah sistolik dan diastolik, serta nadi sebelum pijat kaki

\begin{tabular}{llll}
\hline No & Sistolik & Diastolik & Nadi \\
\hline & & & \\
1 & 122 & 71 & 65 \\
2 & 124 & 67 & 66 \\
3 & 120 & 71 & 57 \\
4 & 118 & 63 & 63 \\
5 & 116 & 66 & 60 \\
6 & 120 & 72 & 60 \\
7 & 122 & 72 & 71 \\
8 & 124 & 80 & 63 \\
9 & 119 & 75 & 78 \\
10 & 126 & 78 & 59 \\
11 & 122 & 76 & 67 \\
12 & 126 & 69 & 65 \\
13 & 110 & 76 & 68 \\
14 & 128 & 82 & 86 \\
15 & 119 & 73 & 59 \\
16 & 128 & 67 & 72 \\
17 & 120 & 76 & 55 \\
18 & 131 & 77 & 65 \\
19 & 121 & 68 & 53 \\
20 & 115 & 78 & 64 \\
\end{tabular}

Rata-rata tekanan darah sistolik, tekanan darah diastolik, dan nadi sesudah dilakukan pijat kaki ditunjukkan dalam tabel 4 .

Tabel 4. Rata-rata tekanan darah dan nadi sesudah pijat kaki

\begin{tabular}{lll}
\hline Parameter & Mean & SD \\
\hline TD Sistalik & 131.50 & 5.196 \\
TD Diastalik & 83.55 & 2.700 \\
Nadi & 71.60 & 6976 \\
\hline
\end{tabular}

Perbedaan rata-rata tekanan darah sistolik, diastolik dan nadi antara hasil pre test dan post test pijat kaki ditunjukkan pada tabel 5.
Tabel 5. Perbedaan tekanan darah dan nadi pre dan post pijat kaki.

\begin{tabular}{lccccc}
\hline Parameter & Mean & SD & $\boldsymbol{t}$ & $\boldsymbol{p}$ & $\mathbf{d}$ \\
\hline Sistalik & & & & & \\
Pre & 131.50 & 5.196 & 13.16 & .000 & 2.94 \\
Post & 121.55 & 4.946 & & & \\
Diastalik & & & & & \\
Pre & 83.65 & 2.700 & 10.33 & .000 & 2.31 \\
Post & 72.85 & 5.122 & & & \\
Nadi & & & & & \\
Pre & 71.60 & 6.976 & 6.77 & .000 & 1.51 \\
Post & 64.80 & 7.770 & & & \\
\hline
\end{tabular}

\section{PEMBAHASAN}

Rata-rata tekanan darah sistolik sebelum pijat kaki adalah $131.50 \mathrm{mmHg}$, dan ratarata tekanan darah diastolik sebelum pijat kaki adalah $83.65 \mathrm{mmHg}$. Kedua tekanan darah ini termasuk pada kategori prehipertensi. Dilain pihak rata-rata nadi sebelum pijat kaki adalah $71.60 \mathrm{kali} / \mathrm{menit}$, ini merupakan nadi normal saat istirahat. Setelah dilakukan pemijatan pada kaki selama 30 menit, rata-rata tekanan darah sistolik menjadi $121.55 \mathrm{mmHg}$ dan tekanan darah diastolik menjadi $72.85 \mathrm{mmHg}$. Angka ini menunjukkan penurunan nilai tekanan darah baik sistolik maupun diastolik. Walaupun tekanan sistolik tetap pada kategori prehipertensi, tekanan diastolik mencapai batasan angka tekanan darah optimal. Rata-rata nadi sesudah pijat kaki menjadi 64.80 kali/ menit, hal ini menunjukkan penurunan namun masih tetap pada batasan nadi normal.

Uji statistik dengan paired t-test untuk ratarata tekanan darah sistolik sebelum dan sesudah pijat kaki $p=.000$ dan cohen's $d=$ 2.94. Pada rata-rata tekan darah diastolik $p=.000$ dengan cohen's $d=2.31$. Demikian juga pada rata-rata nadi $p=.000$ dengan cohen's $d=1.51$. Hal ini mengindikasikan perbedaan signifikan antara rata-rata tekanan darah sistolik, diastolik, dan nadi 
sebelum dan sesudah dilakukan pijat kaki $(p=<.005)$ dengan ukuran efek yang besar $(d>.8=$ large effect size $)$. Hasil ini menyatakan bahwa pijat kaki selama 30 menit memberikan efek langsung penurunan tekanan darah sitolik, tekanan darah diastolik, dan nadi.

Fakta yang dihasilkan dalam penelitian ini sesuai dengan penelitian terdahulu yang menginvestigasi tekanan darah dan denyut jantung pada pasien di ruang cardiac intensive care unit sebelum dan sesudah 20 menit pemijatan pada kaki. Hasilnya menunjukkan perubahan signifikan pada tekanan darah sistol dan diastol serta nadi sebelum dan sesudah peminjatan kaki (Abdi. Oshvandi, Karampourian, Moghim, \& Homayoon, 2016). Penelitian lain yang dilakukan oleh Rezky, Hasneli dan Hasanah (2015) pada penderita hipertensi dengan pemberian pijat refleksi kaki menurunkan tekanan darah sistolik sebanyak $6 \mathrm{mmHg}$ dan diastolik $4 \mathrm{mmHg}$. Hartutik dan Suratih (2017) membandingkan pemberian pijat refleksi kaki pada penderita hipertensi primer dengan kelompok kontrol yang tidak diberikan terapi. Hasilnya menunjukkan penurunan tekanan darah pada kelompok terapi.

Secara fisiology, tekanan darah dan nadi dipengaruhi oleh sistem saraf otonom dalam hal ini saraf simpatis dan para simpatis. Saraf simpatis bersifat meningkatkan denyut kecepatan denyut jantung atau nadi serta berpengaruh pada tekanan darah. Sedangkan saraf parasimpatis bekerja sebaliknya (Medic, 2016). Pada individu yang mengalami peningkatan tekanan darah seperti kondisi prehipertensi terjadi peningkatan aktivitas pusat simpatis dan perubahan pada fungsi saraf parasimpatis (Mancia \& Grassi).
Penurunan tekanan darah sistolik maupun diastolik serta penurunan kecepatan nadi setelah dilakukan pemijatan pada kaki merupakan pengaruh dari sistem saraf simpatis. Beberapa peneliti sebelumnya (Sakuragi, 2014; Kito \& Suzuki, 2016; Naseri, et al., 2016; Khalili, et al., 2016) yang melakukan penelitian berbeda-beda dengan intervensi pijat kaki menegaskan bahwa pijat kaki dapat memberi efek relaksasi. Relaksasi terjadi oleh adanya stimulasi taktil dijaringan tubuh. Menurut Lee, Park dan Kim (2011), pemijatan pada bagian tubuh dapat mempengaruhi kerja saraf simpatis, sehingga terjadi relaksasi tubuh, penurunan serum kortisol dan epinefrin. Berkurangnya kerja saraf simpatis, menimbulkan vasodilatasi pembuluh darah perifer, dengan demikian terjadi penurunan tekanan darah dan heart rate (Vicar et al. dalam Ramos et al. 2015).

\section{KESIMPULAN}

Berdasarkan hasil penelitian, dapat disimpulkan bahwa tekanan darah dan nadi klien prehipertensi mengalami penurunan setelah pijat kaki selama 30 menit. Penelitian lebih lanjut dengan sampel yang lebih besar dengan menambahkan frekuensi pemijatan diperlukan untuk melihat hasil yang lebih maksimal.

\section{DAFTAR PUSTAKA}

Abdi, S., Oshvandi, K., Karampourian, A., \& Moghim, A. B., \& Homayoon, S. F. (2016). The effect of foot massage on blood pressure and heart rate of $C C U$ patients. $J$ Urmia Nurs Midwifery Fac, 14 (1):47-55 
Berg, S. (2017). Half of young adults with high BP go untreated. AMA WIRE. Available at: https://wire. amassn.org/delivering-care/halfyoung-adults-high-bp-gountreated

Daniels, R., \& Nicoll, L. H. (2012). Contemporary Medical Surgical Nursing ( $2^{\text {nd }}$ ed). USA: Cengage Learning.

Embong, N. H., Soh, Y. C., Ming, L. C., \& Wong T. W. (2015). Revisiting reflexology: Concept, evidence, current practice, and practitioner training. $J$ Tradit Complement Med. 2015 Oct; 5(4): 197-206. doi: 10.1016/j.jtcme.2015.08.008

Hartutik, S., \& Suratih, K. (2017). Pengaruh terapi pijat refleksi kaki terhadap tekanan darah pada penderita hipertensi primer. GASTER Vol. XV No. 2. http://www.jurnal.stikesaisyiyah.ac.id/index.php/gaster/art icle/view/199/133

Herliawati. (2011). Pengaruh masase kaki dengan menggunakan minyak esensial lavender terhadap penurunan tekanan darah penderita hiprtensi primer usia 45-49 dikelurahan Timbangan Kecamatan Indralaya Utara Kabupaten Ogan Hilir. [Online]. Available:

http://www.eprints.unsri.abstr act.ac.id

Khalili, A., Alavi, N. M., Mardani, D., 3, Pour, N. B., Paymard, A., Daraei, M., Yaripoor, S., ... et al. (2016). The effect of foot reflexology on physiological parameters International Journal of Medical Research \& Health Sciences, 2016, $5,9: 50-54$

Kini, S., Kamath, V. G., Kulkarni, M. M., Kamath, A., \& Shivalli, S. (2016) Pre-Hypertension among Young Adults (20-30 Years) in Coastal Villages of Udupi District in Southern India: An Alarming Scenario. https://doi.org/10.1371/journal.po $\underline{\text { ne. } 0154538}$

Kito, K., \& Suzuki, K. (2016). Research on the Effect of the Foot Bath and Foot Massage on Residual Schizophrenia Patients. Arch Psychiatr Nurs. 2016 Jun;30(3):375-81. doi: 0.1016/j.apnu.2016.01.002.

Lee, Y-H., Park, B. N. R.n \& Kim, S. H. (2011). The Effects of Heat and Massage Application on Autonomic Nervous System. Yonsei Med J. 2011 Nov 1; 52(6): 982989.

doi: $10.3349 / y m j .2011 .52 .6 .982$

Mancia, G. \& Grassi, G. (2014). The autonomic nervous system and hypertension. Circ Res. 2014;114:1004-1021.

Medic, B. (2016). The role of autonomic control in cardiovascular system: summary of basic principles. Medical Youth, 67(1):14-18

Moyle, W., Cooke, M. L., Beattie, E., Shum, D. H. K., O'Dwyer, S. T., Barrett, S., \& Sung, B. (2014). Foot Massage and Physiological 
Stress in People with Dementia: A Randomized Controlled Trial. J Altern Complement Med. 2014 Apr 1; 20(4): 305-311. doi: $10.1089 / \mathrm{acm} .2013 .0177$

Mubarak, W. I., Inrawati, L. \& Susanto, J. 92015). Buku Ajar: Ilmu Keperawatan Dasar, Buku 1. Jakarta:Salemba Medika

Mucci, N., Giorgi, G., Ceratti, S. D. P., Fiz-Pérez, J. Mucci, F., \& Arcangeli, G. (2016). Anxiety, Stress-Related Factors, and Blood Pressure in Young Adults. Front Psychol. 2016; 7: 1682. doi: 10.3389/fpsyg.2016.01682

Naseri, M., Rahmani, A., Nerir, B., Salari, M., \& Farahani, M. M., (2016). Effect of Foot Reflexology Massage and Foot Bath on the Sleep Quality of Patients with Acute Coronary Syndrome: A Comparative Study, Crit Care Nurs J. 2016 ;9(4):e10294. doi: 10.17795/ccn-10294.

Porth, C. M., (2011). Essential of pathophysiology: Concept of altered health states. USA: Lippincott Williams \& Wilkins.

Puspitorini, M. (2008). Hipertensi cara mudah mengatasi tekanan darah tinggi. Jogjakarta: Image Press.

Ramos DG, Alimboyao SV, Dompiles AD, Nazarro EG, Pascua NM, et al. (2015) The Effect of Kolkolis in Reducing Blood Pressure. Int J Nephrol Kidney Failure 1(3): doi http://dx.doi. org/10.16966/23805498.112
Reule, S. \& Drawz, P. E. (2012). Heart rate and blood pressure: any possible implications for management of hypertension? Curr Hypertens Rep, 14 (6):478484 doi: 10.1007/s11906-0120306-3

Rezky, R. A., Hasneli, Y., \& Hasanah, O. (2015) Pengaruh Terapi Pijat Refleksi Kaki Terhadap Tekanan Darah Penderita Hipertensi Primer. JOM, 2(2). https://jom.unri.ac.id/index.php/J OMPSIK/article/view/8319/7988

Sakuragi (2014) Effects of Foot-Massage on Mood and Autonomic Nervous System and the Interaction with Personality. Int J Sch Cog Psychol 1:112. doi:10.4172/24699837.1000112

Senthil, S., \& Krishnadas, S. N. (2016). Prehypertension and Its Determinants in Apparently Healthy Young Adults. J Clin Diagn Res. 2016 Sep; 10(9): CC05-CC08. doi: 10.7860/JCDR/2016/20626.8447

Wahyuni, S. (2014). Pijat refleksi untuk kesehatan. Jakarta Timur: Dunia Sehat

Yoon, S. S., Burt, V., Louis. T., \& Carroll, M.D (2012). Hypertension among adults in the United States, 20092010. NCHS Data Brief. 2012; 107:1-8.

Zhang, Y. \& Moran A. E. (2017). Trends in the prevalence, awareness, treatment, and Control of hypertension among Young adults 
in the United stated, 1999 to 2014.

HYPERTENSIONAHA. Doi.

117.09801

38 | Jurnal Skolastik Keperawatan | Vol.4, No.1 | Jan - Jun 2018 